Article

\title{
Functional Characterization of a Putative RNA Demethylase ALKBH6 in Arabidopsis Growth and Abiotic Stress Responses
}

\author{
Trinh Thi Huong ${ }^{1,2}$, Le Nguyen Tieu Ngoc ${ }^{1,3}$ and Hunseung Kang ${ }^{1, *}$ \\ 1 Department of Applied Biology, College of Agriculture and Life Sciences, Chonnam National University, \\ Gwangju 61186, Korea; trinhhuongwasi@gmail.com (T.T.H.); tieungocdhtn@gmail.com (L.N.T.N.) \\ 2 The Western Highlands Agriculture and Forestry Science Institute, Buon Ma Thuot, DakLak 63000, Vietnam \\ 3 Faculty of Forestry Agriculture, Tay Nguyen University, Buon Ma Thuot, DakLak 63000, Vietnam \\ * Correspondence: hskang@jnu.ac.kr; Tel.: +82-(62)-530-2181
}

Received: 9 September 2020; Accepted: 11 September 2020; Published: 13 September 2020

\begin{abstract}
RNA methylation and demethylation, which is mediated by RNA methyltransferases (referred to as "writers") and demethylases (referred to as "erasers"), respectively, are emerging as a key regulatory process in plant development and stress responses. Although several studies have shown that AlkB homolog (ALKBH) proteins are potential RNA demethylases, the function of most ALKBHs is yet to be determined. The Arabidopsis thaliana genome contains thirteen genes encoding ALKBH proteins, the functions of which are largely unknown. In this study, we characterized the function of a potential eraser protein, ALKBH6 (At4g20350), during seed germination and seedling growth in Arabidopsis under abiotic stresses. The seeds of T-DNA insertion alkbh6 knockdown mutants germinated faster than the wild-type seeds under cold, salt, or abscisic acid (ABA) treatment conditions but not under dehydration stress conditions. Although no differences in seedling and root growth were observed between the alkbh6 mutant and wild-type under normal conditions, the alkbh6 mutant showed a much lower survival rate than the wild-type under salt, drought, or heat stress. Cotyledon greening of the alkbh6 mutants was much higher than that of the wild-type upon ABA application. Moreover, the transcript levels of ABA signaling-related genes, including $A B I 3$ and $A B I 4$, were down-regulated in the alkbh6 mutant compared to wild-type plants. Importantly, the ALKBH6 protein had an ability to bind to both $\mathrm{m}^{6} \mathrm{~A}$-labeled and $\mathrm{m}^{5} \mathrm{C}$-labeled RNAs. Collectively, these results indicate that the potential eraser ALKBH6 plays important roles in seed germination, seedling growth, and survival of Arabidopsis under abiotic stresses.
\end{abstract}

Keywords: RNA demethylation; RNA methylation; ALKBH; abiotic stress; epitranscriptomics; Arabidopsis

\section{Introduction}

RNA modifications are recently emerging as an important cellular process of epigenetic gene regulation in addition to DNA methylation and histone modifications [1,2]. Approximately 160 RNA modifications in mRNAs, tRNAs, and rRNAs have been identified to date [3,4], among which the most abundant modifications are $2^{\prime}$-O-ribose methylation and pseudouridilation in rRNA, 5-methylcytosine $\left(\mathrm{m}^{5} \mathrm{C}\right)$ and 1-methylguanidine $\left(\mathrm{m}^{1} \mathrm{G}\right)$ in tRNA, and $\mathrm{N}^{6}$-methyladenine $\left(\mathrm{m}^{6} \mathrm{~A}\right)$ in mRNA [4-7]. These modifications affect the chemical property, charge, and hydrophobicity of bases, which influence base stacking, base pairing, and interactions of RNAs with other molecules [5,7-9]. RNA methylations have essential roles in ribosome structure and biogenesis, codon recognition and decoding, reading frame maintenance, and translation initiation and elongation [6,10-15].

RNA methylation is modulated by RNA methyltransferases (referred to as "writers") and demethylases (referred to as "erasers") that install and remove methylation marks, respectively 
(reviewed in [16-18]). These methylated marks are recognized by RNA-binding proteins, referred to as "readers" [2,16,18]. Many recent studies have demonstrated the essential roles of writer components, including MTA, MTB, VIR, HAKAI, and FIP37, and several reader proteins, including ECT2, ECT3, and ECT4, involved in mRNA m ${ }^{6}$ A methylation and interpretation in plants (reviewed in [16-19]). Through the analysis of the mutants of these writers and erasers, it has been demonstrated that $\mathrm{m}^{6} \mathrm{~A}$ methylation in mRNAs is crucial for plant growth and development [20-25]. By contrast, the identity, biological functions, and cellular roles of eraser proteins are largely unknown. The AlkB homolog (ALKBH) proteins, which are members of the alpha-ketoglutarate $(\alpha \mathrm{KG})$ and $\mathrm{Fe}(\mathrm{II})$-dependent dioxygenase superfamily and can remove alkyl and methyl groups from DNAs, have been suggested to function as RNA demethylases [26,27]. Mammals have nine different ALKBH family members: ALKBH1 to ALKBH8 and the fat mass and obesity-associated (FTO) protein [28-32]. Among them, human ALKBH5 and FTO protein have been demonstrated to function as $\mathrm{m}^{6} \mathrm{~A}$ demethylases, which are involved in obesity, diabetes, and hypoxia response [33,34].

In plants, the role of eraser proteins has been determined in only a few cases. Thirteen Arabidopsis ALKBH family members have been identified by bioinformatics analysis [30,32]. Among them, the role of ALKBH9B and ALKBH10B has been demonstrated; ALKBH10B was identified as an mRNA $\mathrm{m}^{6} \mathrm{~A}$ eraser, influencing floral transition [35], and ALKBH9B was shown to affect methylation of alfalfa mosaic virus RNA, mediating systemic infection [36]. A recent study demonstrated that mutation of SlALKBH2, an RNA demethylase in tomato (Solanum lycopersicum), delays fruit ripening [37]. However, the role of erasers in the response of plants to abiotic stresses has yet to be determined, albeit the expression patterns of $A L K B H$ genes in response to abiotic stresses have been explored [16,38,39].

Given that the function of most ALKBHs still remains unknown, it is a worthwhile endeavor to determine their roles in plant growth and stress responses. As no information about the role of ALKBH6 is known in either the plant or animal system, we aimed to determine the function of ALKBH6 in growth and abiotic stress response in Arabidopsis. We show that ALKBH6 plays important roles in seed germination, seedling growth, and survival of Arabidopsis under abiotic stresses.

\section{Results}

\subsection{The Domain Structure, Subcellular Localization, and Stress-Responsive Expression Pattern of ALKBH6 in Arabidopsis}

Analysis of the putative ALKB domain-containing proteins in the Arabidopsis genome database (http://arabidopsis.org) revealed 13 genes encoding ALKBH family members that harbor a 2-oxoglutarate-Fe(II)-Oxy-2 domain (Figure S1). ALKBH6 is a relatively small ALKBH family protein comprising 241 amino acid residues (Figure 1A). Subcellular localization of the ALKBH6 protein was investigated by transiently expressing the ALKBH6-green fluorescence protein (GFP) fusion protein in tobacco leaves. The results showed that the GFP signals were clearly merged with the $4^{\prime}, 6$-diamidino-2-phenylindole (DAPI) signals that stain the nucleus (Figure 1B), indicating that ALKBH6 is localized in the nucleus. To obtain clues on the possible function of ALKBH6 in stress responses, the expression levels of ALKBH6 were analyzed in Arabidopsis under different abiotic stresses and in the presence of abscisic acid (ABA). Successful application of the stress to the plants was verified by observing a marked increase in the transcript levels of stress marker genes, including $R D 29 \mathrm{~A}$ for drought stress, SUS for salt stress, HSP70 for heat stress, CBF2 for cold stress, and RD29B for ABA (Figure S2). The expression level of $A L K B H 6$ was increased up to fourfold under salt stress, whereas its level was decreased by cold stress. By contrast, heat stress, drought stress, or ABA treatment did not affect $A L K B H 6$ expression (Figure 1C). These results suggest that ALKBH6 is involved in diverse abiotic stress responses. 

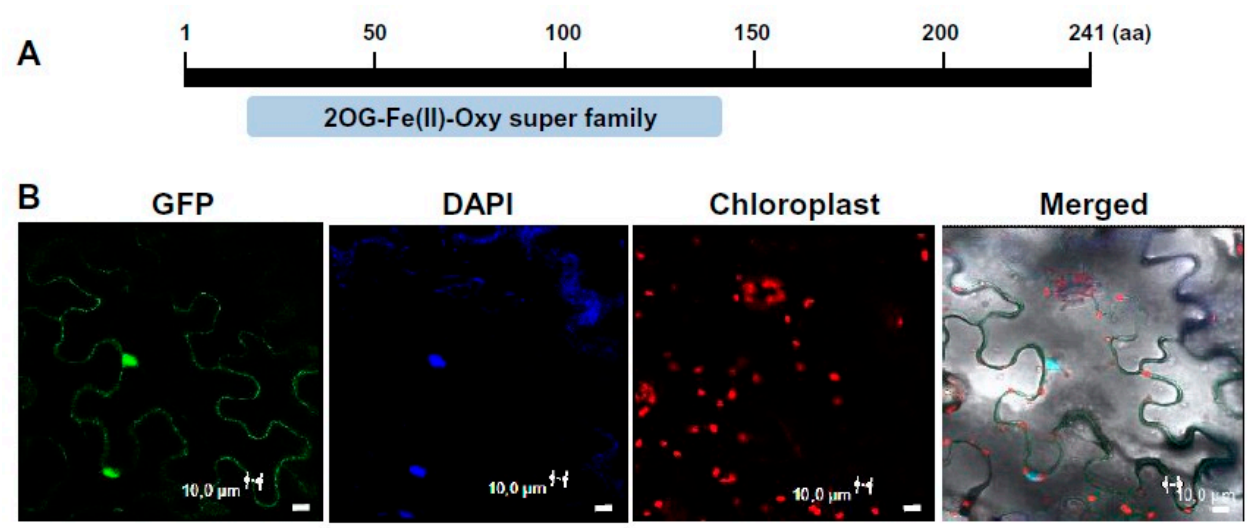

C

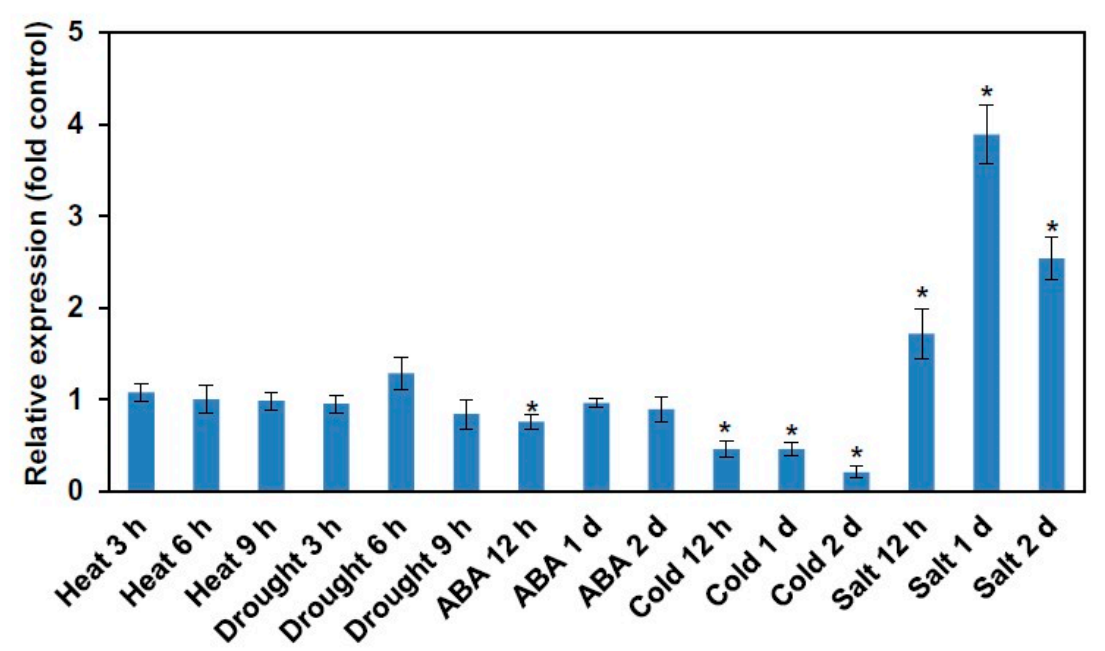

Figure 1. Subcellular localization and stress-responsive expression patterns of ALKBH6. (A) Schematic representation of the domain structure of ALKBH6. The conserved 2-oxoglutarate (2OG) and Fe(II)-dependent oxygenase (Oxy) domain is shown. aa, amino acid. (B) The ALKBH6-green fluorescence protein (GFP) fusion protein was transiently expressed in tobacco leaves, and the fluorescence signals were detected using a confocal microscope. 4',6-diamidino-2-phenylindole (DAPI) was used to stain the nucleus, and the red signals indicate chloroplast auto-fluorescence. Bar $=10 \mu \mathrm{m}$. (C) Two-week-old Arabidopsis seedlings were subjected to drought, heat $\left(42^{\circ} \mathrm{C}\right)$, cold $\left(10^{\circ} \mathrm{C}\right)$, high salinity $(300 \mathrm{mM} \mathrm{NaCl})$, or abscisic acid (ABA) $(100 \mu \mathrm{M})$ treatment, and the transcript levels of $A L K B H 6$ were determined via real-time RT-PCR. Values are the mean \pm SE obtained from three independent experiments, and the asterisks above columns indicate significant differences ( $\left.{ }^{*} p \leq 0.05\right)$.

\subsection{ALKBH6 Affects Seed Germination and Seedling Growth under Abiotic Stresses}

To determine the function of ALKBH6 in the growth and stress response of Arabidopsis, two T-DNA insertion mutants, SALK_105865C and SALK_138864C that contain the T-DNA insert in the last intron and the last exon, respectively (Figure S3A), were analyzed. Genotyping of the two mutants via genomic DNA PCR confirmed that both mutants were homozygous lines (Figure S3B). Analysis of the level of $A L K B H 6$ transcript in the two analyzed mutant backgrounds via RT-PCR and qRT-PCR showed that the expression of $A L K B H 6$ in both mutant backgrounds was approximately $10-20 \%$ of the wild-type level (Figure S3C,D). These results indicate that the two alkbh6 mutants are knockdown mutants.

We first analyzed the rate of seed germination of wild-type plants and the alkbh6 mutants under normal conditions, abiotic stresses, and ABA. The results showed that no differences in seed germination were observed between wild-type and alkbh6 mutants under normal conditions (Figure S4). However, germination rates of the alkbh6 mutants were enhanced compared to those of wild-type under salt or cold stress, as well as in the presence of ABA, but not under dehydration stress (Figure S4). These results 
indicate that ALKBH6 plays as a negative regulator of seed germination under salt or cold stress and in the presence of ABA.

We next analyzed the seedling and root growth of wild-type plants and alkbh6 mutants under normal and abiotic stress conditions. No visible differences in overall growth were observed between wild-type plants and alkbh6 mutants under normal growth conditions (Figure S5). When the plants were grown on solid Murashige and Skoog (MS) medium supplemented with 200-400 mM mannitol, the fresh weight and root length of the alkbh6 mutants was similar to those of the wild-type plants (Figure 2A). However, when the 20-day-old seedlings grown in soil were subjected to drought stress by withholding watering, the survival rate of the alkbh6 mutants was significantly lower than that of the wild-type (Figure 2B and Figure S6). These results indicate that ALKBH6 is a positive regulator of plant survival under drought stress.

A

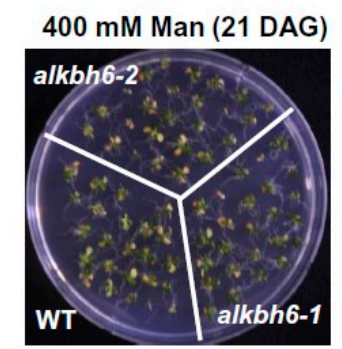
200 mM Man (14 DAG)
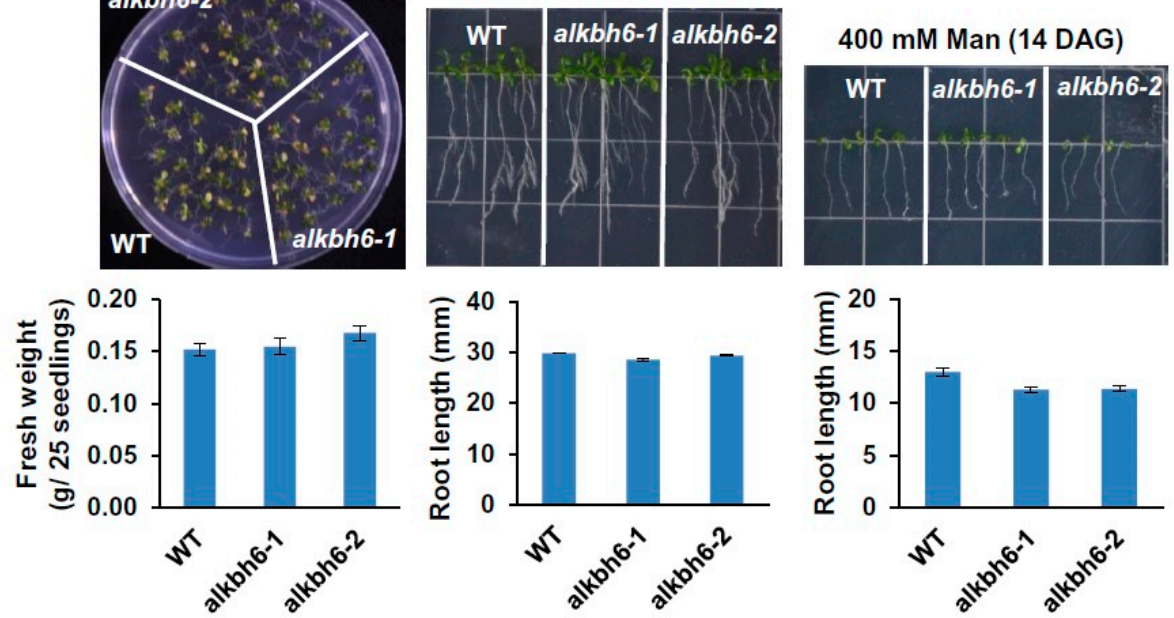

B

Before drought

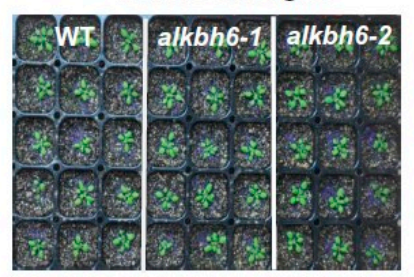

13 days without water

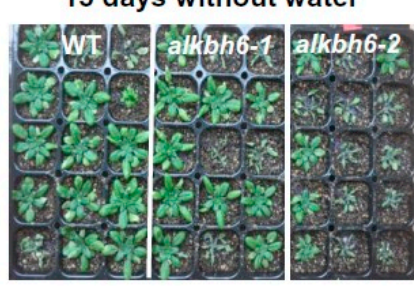

3 days after recovery

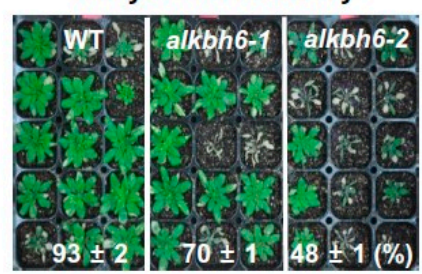

Figure 2. Seedling and root growth of the alkbh6 mutants under drought stress. (A) The wild-type (WT) and alkbh6 mutants were grown on the (Murashige and Skoog) MS medium supplemented with 200 or $400 \mathrm{mM}$ mannitol, and the fresh weight and root length of the seedlings were measured at the indicated days after germination (DAG). (B) Twenty-day-old seedlings grown in soil were subjected to drought stress for 13 days, and survival rates were measured 3 days after recovery. Values are the mean \pm SE obtained from three independent experiments.

Under salt stress on solid MS medium supplemented with 100-150 $\mathrm{mM} \mathrm{NaCl}$, the fresh weight and root length of the alkbh6 mutants were similar to those of wild-type Arabidopsis (Figure 3A), whereas the survival rate of the alkbh6 mutants was significantly higher than that of the wild-type (Figure 3B). No visible differences in seedling and root growth were observed between the wild-type and alkbh6 mutants under cold stress (Figure 4A). By contrast, the seedling growth and survival rates of the alkbh6 mutants were significantly lower than those of the wide type under heat stress; the survival rate of the wild-type and mutants after $45^{\circ} \mathrm{C}$ heat treatment for $4 \mathrm{~h}$ were approximately $80 \%$ and $40 \%$, respectively (Figure 4B). Collectively, these results indicate that ALKBH6 is a positive regulator of plant survival under drought or heat stress but a negative regulator of plant survival under salt stress. 
A
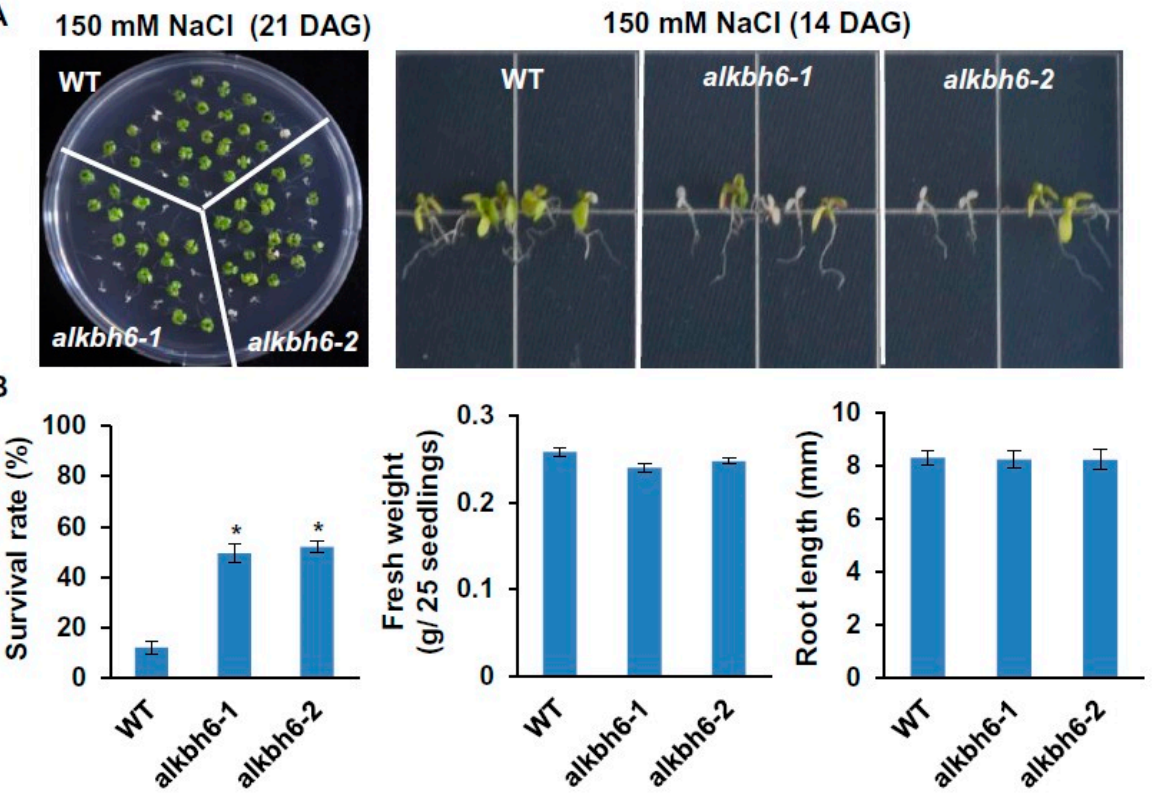

Figure 3. Seedling and root growth of the alkbh6 mutants under salt stress. (A) Wild-type Arabidopsis (WT) and alkbh6 mutants were grown on solid MS medium supplemented with $150 \mathrm{mM} \mathrm{NaCl}$, and photographs for seedlings and roots were taken at the indicated days after germination (DAG). (B) Survival rate and fresh weight were measured 21 DAG, and root lengths were measured 14 DAG. Values are the mean \pm SE obtained from three independent experiments, and the asterisks above columns indicate significant differences $\left.{ }^{*} p \leq 0.05\right)$.
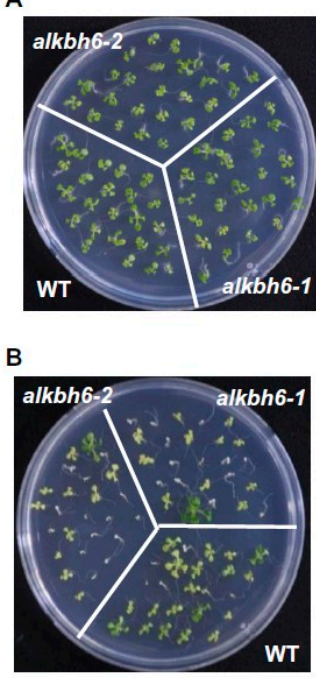

Cold $\left(10^{\circ} \mathrm{C}\right)$

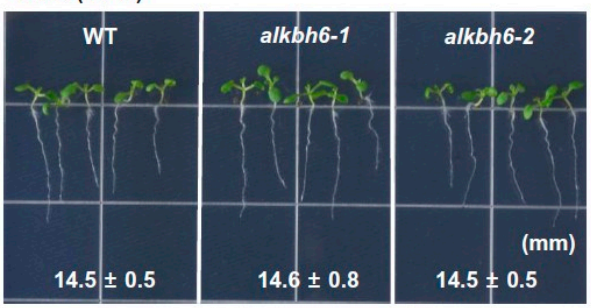

Heat $\left(45^{\circ} \mathrm{C}\right)$

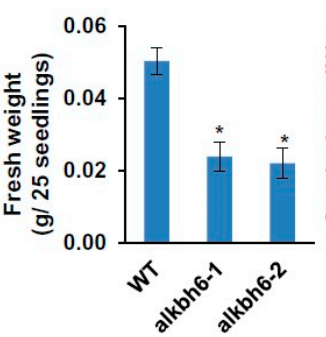

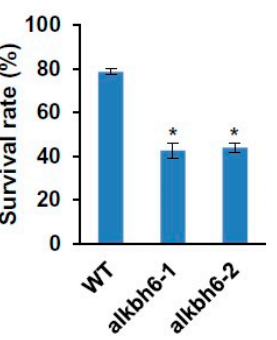

Figure 4. Seedling and root growth of the alkbh6 mutants under cold or heat stress. (A) The wild-type (WT) and alkbh6 mutants were grown at $10{ }^{\circ} \mathrm{C}$, and root lengths were measured four weeks after germination. (B) Three-day-old seedlings were treated at $37^{\circ} \mathrm{C}$ for $1 \mathrm{~h}$ and then subjected to heat stress at $45{ }^{\circ} \mathrm{C}$ for $4 \mathrm{~h}$. Survival rate and fresh weight of the plants were measured seven days after heat treatment. Values are the mean \pm SE obtained from three independent experiments, and the asterisks above columns indicate significant differences $(* p \leq 0.05)$.

\subsection{ALKBH6 Influences the Response of Arabidopsis to ABA}

To determine whether ALKBH6 plays a role in ABA response, the growth of seedlings and roots of the plant lines was analyzed in the presence of different concentrations of ABA. When the wild-type and 
alkbh6 mutants were grown on solid MS medium supplemented with 2 or $4 \mu \mathrm{M}$ ABA, the fresh weight, cotyledon greening, and root lengths of the alkbh6 mutants were significantly elevated compared to corresponding measurements determined for wild-type Arabidopsis (Figure 5A,B). To ascertain how ALKBH6 affects the seedling growth of Arabidopsis in the presence of ABA, the expression levels of ABA biosynthesis- and ABA signaling-related genes were analyzed via qRT-PCR in the wild-type and alkbh6 mutants upon ABA application. The results showed that the levels of the ABA biosynthesis-related genes, including $A B A 1, A B A 2, A B A 3, A B A 4$, and NCED3, were not altered in the alkbh6 mutants upon ABA application (Figure $5 \mathrm{C}$ ), whereas the levels of the ABA signaling-related genes, including $A B I 3$ and $A B I 4$, were significantly decreased in the mutants compared to those in the wild-type (Figure 5D). These results indicate that ALKBH6 affects ABA response via modulation of the expression of ABA signaling-related genes.
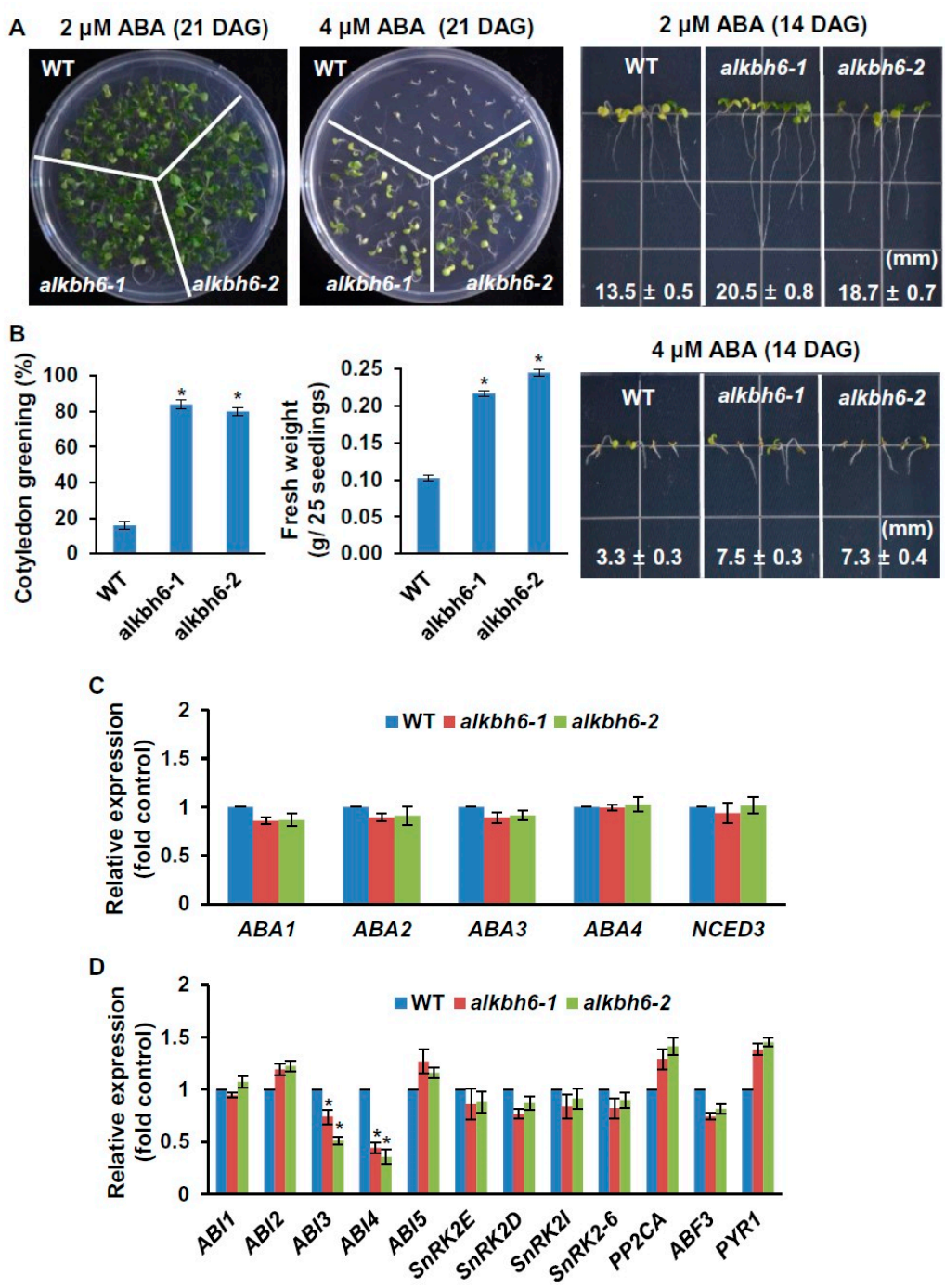

Figure 5. Effects of ABA on the seedling and root growth of the alkbh6 mutants. (A) Growth of wild-type (WT) plants and alkbh6 mutants was observed on solid MS medium supplemented with 2 or $4 \mu \mathrm{M}$ ABA. (B) Cotyledon greening and fresh weight of the assessed plant lines were measured two and three weeks after germination, respectively. The transcript levels of (C) ABA biosynthesis-genes and (D) ABA signaling-related genes in 3-week-old seedlings were determined via qRT-PCR. Values are the mean \pm SE obtained from three independent experiments, and the asterisks above columns indicate significant differences $\left({ }^{*} p \leq 0.05\right)$. 


\subsection{ALKBH6 Binds to the RNA with $m^{6} A$ or $m^{5} C$ Modification}

The next important question we aimed to answer was, what is the RNA target of ALKBH6? Because no information is currently available for the potential RNA target of ALKBH6, we first analyzed whether the $\mathrm{m}^{6} \mathrm{~A}$ or $\mathrm{m}^{5} \mathrm{C}$ level was altered in the alkbh6 mutants using the commercially available $\mathrm{m}^{6} \mathrm{~A}$ and $\mathrm{m}^{5} \mathrm{C}$ assay kits. The results showed no significant differences in $\mathrm{m}^{6} \mathrm{~A}$ and $\mathrm{m}^{5} \mathrm{C}$ levels between the wild-type and alkbh6 mutants (Figure S7).

Although the knockdown of the expression level of ALKBH6 did not alter the $\mathrm{m}^{6} \mathrm{~A}-$ and $\mathrm{m}^{5} \mathrm{C}$-level, we next evaluated whether ALKBH6 can bind to an $\mathrm{m}^{6} \mathrm{~A}$ - or $\mathrm{m}^{5} \mathrm{C}$-modified RNA. The recombinant ALKBH6 protein was purified, which contained ALKBH6 and a small amount of His-tag-Trigger factor present in the pCold trigger factor (TF) DNA vector (Figure S8). The $5^{\prime}$-fluorescein-labeled RNA substrates were synthesized and used in an electrophoretic mobility shift assay (EMSA). Two $\mathrm{m}^{6} \mathrm{~A}$-labeled RNA substrates were used in this assay; one RNA substrate containing a conserved RRACH motif ( $\mathrm{R}=\mathrm{G} / \mathrm{A}, \mathrm{H}=\mathrm{U} / \mathrm{A} / \mathrm{C})$, which was derived from the Arabidopsis Salt Overly Sensitive 3 (SOS3) RNA (5'-GAAUCCGAm ${ }^{6}$ ACUAGUUCU-3' and 5'-GAAUCCGAACUAGUUCU-3') [40], and another RNA substrate containing a conserved UACAGAGA motif, which was derived from the human S-adenosylmethionine synthase (MAT2A) RNA (5'-CGUAGGCUACm ${ }^{6}$ AGAGAAGCCUU- $3^{\prime}$ and $5^{\prime}$-CGUAGGCUACAGAGAAGCCUU- ${ }^{\prime}$ ) [41]. The $\mathrm{m}^{5} \mathrm{C}$-labeled RNA substrate was derived from the conserved $\mathrm{m}^{5} \mathrm{C}$ motif found in Arabidopsis (5'-GGACGCUUm ${ }^{5}$ CUUCGACCU-3' and $5^{\prime}$-GGACGCUUCUUCGACCU-3') [42]. The results of the EMSA showed that the addition of ALKBH6 retarded the migration of both $\mathrm{m}^{6} \mathrm{~A}$-labeled- and unlabeled-RNAs, as well as both $\mathrm{m}^{5} \mathrm{C}$-labeled- and unlabeled-RNAs (Figure 6). By contrast, the addition of His-tag-Trigger factor alone did not retard the migration of the RNAs. Collectively, these results indicate that ALKBH6 has an ability to bind to $\mathrm{m}^{6} \mathrm{~A}-$ or $\mathrm{m}^{5} \mathrm{C}$-labeled RNAs, suggesting its possible role as an $\mathrm{m}^{6} \mathrm{~A}$ or $\mathrm{m}^{5} \mathrm{C}$ eraser.

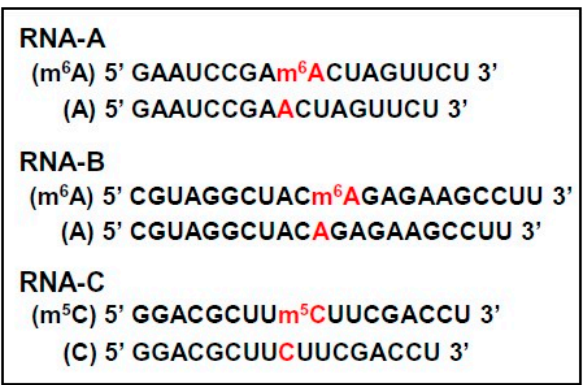

B

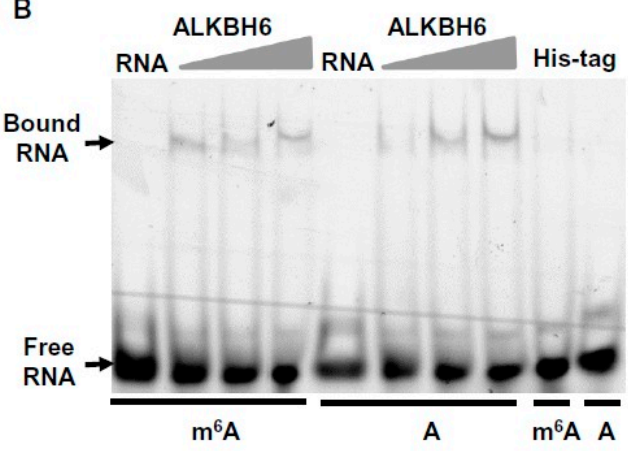

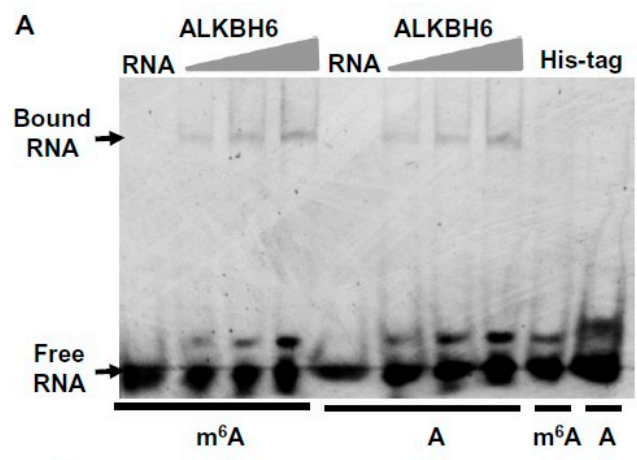

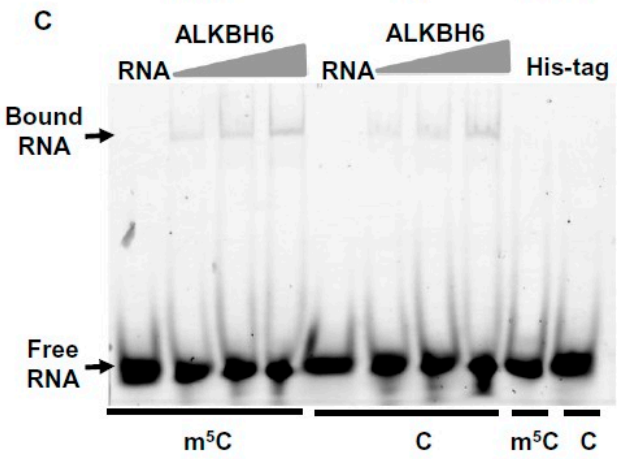

Figure 6. RNA-binding ability of the ALKBH6 protein. Electrophoretic mobility shift assay showing the binding between the ALKBH6 protein $(3,5$, and $7 \mu \mathrm{M})$ and the synthetic (A) RNA-A, (B) RNA-B, or (C) RNA-C. The modified adenine and cytosine bases are indicated in red. The $5^{\prime}$-fluorescein-labeled RNA substrates were mixed with the purified protein, and the reaction mixtures were separated on a $6 \%$ native acrylamide gel. The binding products were detected using an image analyzer. 


\section{Discussion}

RNA demethylation mediated by eraser proteins is emerging as an important cellular process of epigenetic gene regulation in the response of plants to abiotic stresses, as well as in plant development. In particular, the potential role of ALKBHs in stress response has been suggested based on their altered expression patterns upon stress treatment $[16,38,39,43]$. However, the function of most of the potential ALKBH eraser proteins remains unknown. The results presented in this study demonstrate that ALKBH6, one of the 13 AlkB domain-containing proteins encoded by Arabidopsis (Figure S1), plays a role in seed germination and post-germination seedling growth of Arabidopsis under abiotic stresses. Although no differences in seed germination and seedling growth were observed between wild-type Arabidopsis and the alkbh6 mutants under normal conditions (Figures S4 and S5), the alkbh6 knockdown mutants germinated faster than wild-type plants under cold or salt stress, but not under dehydration stress (Figure S4). These results indicate that ALKBH6 negatively influences seed germination under various abiotic stresses. Evidently, the alkbh6 mutants showed a lower survival rate than wild-type plants under drought or heat stress, but a higher survival rate than the wild-type under salt stress (Figures 2-4), indicating that ALKBH6 mediates different roles in the Arabidopsis response to various abiotic stresses. The importance of RNA methylation in stress responses in plants has been demonstrated in only a few cases; OsNUSN2, an mRNA $\mathrm{m}^{5} \mathrm{C}$ methyltransferase in rice, was shown to regulate mRNA translation and maintain chloroplast function, which enhances rice adaptation to heat stress [44], and $\mathrm{m}^{6} \mathrm{~A}$ methylation was associated with the stabilization of the transcripts encoding salt response proteins in response to salt stress [45]. Although we do not know the mechanistic role of ALKBH6 in stress responses, our current results together with these previous findings point to the crucial role of RNA methylation/demethylation in the response of plants to abiotic stresses.

Notably, the alkbh6 mutants were hyposensitive to ABA that inhibits seed germination and the post-germination growth of plants [46]; the seed germination, cotyledon greening, and seedling growth of the alkbh 6 mutants were all elevated compared to these metrics in wild-type plants in the presence of ABA (Figure 5 and Figure S4). The expression levels of ABA signaling-related genes, including $A B I 3$ and $A B I 4$, were significantly decreased in the mutant backgrounds compared to their levels in wild-type plants upon ABA application (Figure 5D). As $A B I 3$ and $A B I 4$ are known to inhibit seed germination and seedling growth of Arabidopsis via ABA signaling [47-52], these results indicate that ALKBH6 acts as a negative regulator of the ABA response via influencing ABA signaling. Although we do not know presently how the transcript levels of $A B I 3$ and $A B I 4$ are decreased in the alkbh6 mutants, a possible clue can be obtained from the observation that RNA methylation is associated with the stability of mRNAs; $\mathrm{m}^{6} \mathrm{~A}$ methylation was shown to either decrease or increase the stability of mRNAs in animals and plants [37,45,53-55]. It is, therefore, likely that ALKBH6-mediated demethylation influences the stability of RNA targets. Further studies are needed to determine whether ALKBH6 either directly or indirectly regulates the levels of $A B I 3$ and $A B I 4$ during ABA response.

Finding RNA targets of an RNA demethylase is crucial for understanding the cellular and mechanistic role of the eraser protein. Previous studies have identified many base methylations in tRNAs [56], rRNAs [57], and mRNAs [4]. In particular, based on a recent advance in transcriptome-wide methylated RNA immunoprecipitation-sequencing (MeRIP-seq), $\mathrm{m}^{6} \mathrm{~A}$ was found to be the most abundant internal modification in eukaryotic mRNAs [2,17]. Three conserved motifs for $\mathrm{m}^{6} \mathrm{~A}$ methylation have been identified to date; the RRACH motif $(R=G / A, H=U / A / C)$ in plants and animals $[35,40,53,58]$, the UG(U/A)A(C/A)H motif in plants [37,59], and the ACAGAGA motif in humans $[41,60]$. Although the writer proteins that install these $\mathrm{m}^{6} \mathrm{~A}$ marks have been identified, the eraser proteins targeting only the RRACH motif have been identified, including the human ALKBH5 and FTO proteins $[33,34]$ and plant ALKBH9B and ALKBH10B proteins $[35,36]$. The function and RNA target of ALKBH6 are unknown in plants as well as in animals [32]. Previous studies have demonstrated that ALKBH6 in humans is localized mainly in the nucleus and also in cytoplasm [30,61], and that ALKBH6 possesses a positively charged surface, suggesting its possible interaction with nucleic acids [62]. Given that the potential RNA target of ALKBH6 is elusive, it will be of worth to 
evaluate the RNA-binding ability of ALKBH6. Our results clearly show that ALKBH6 has an ability to bind to both $\mathrm{m}^{6} \mathrm{~A}$-labeled and $\mathrm{m}^{5} \mathrm{C}$-labeled RNAs (Figure 6), raising the possibility that it may be an $\mathrm{m}^{6} \mathrm{~A}$ or $\mathrm{m}^{5} \mathrm{C}$ eraser. Contrary to this expectation, our results showed that $\mathrm{m}^{6} \mathrm{~A}$ and $\mathrm{m}^{5} \mathrm{C}$ levels are not significantly altered in the alkbh6 mutants (Figure S6). The lack of reduced levels of $\mathrm{m}^{6} \mathrm{~A}$ or $\mathrm{m}^{6} \mathrm{C}$ in the mutants is possibly due to the residual demethylase activity in the alkbh6 knockdown mutants or the limited sensitivity of the commercially available $\mathrm{m}^{6} \mathrm{~A}$ and $\mathrm{m}^{5} \mathrm{C}$ detection kits used in this study. Further analyses of the $\mathrm{m}^{6} \mathrm{~A}$ or $\mathrm{m}^{6} \mathrm{C}$ level in the loss-of-function alkbh6 knockout mutant and via using a more sensitive RNA methylation analysis method, such as LC-MS/MS, are needed to prove this possibility. Given that ALKBH6 is localized in the nucleus (Figure 1), it is likely that ALKBH6 is involved in the maintenance of proper levels of RNA methylation in the nucleus, which affects the processing or stability of target RNAs. The next critical experiments will be to characterize the demethylase activity of ALKBH6 and to determine whether ALKBH6 targets mRNA, rRNA, or tRNA. Owing to recent advances in novel technologies for detecting and mapping RNA modifications, including MeRIP-seq, $\mathrm{m}^{6} \mathrm{~A}$-CLIP/miCLIP, $\mathrm{m}^{6} \mathrm{~A}$-LAIC-seq, and PA-m ${ }^{6} \mathrm{~A}$-seq [17], it is practically feasible, albeit not easy, to identify RNA targets of an eraser protein. An additional future major task is to utilize these technologies to map the transcriptome-wide methylation status of RNAs in the alkbh6 mutant background and in other eraser mutant backgrounds, which will provide crucial information to furthering our understanding of the cellular roles of ALKBH eraser proteins in plants.

\section{Materials and Methods}

\subsection{Plant Materials and Growth Conditions}

A. thaliana Columbia-0 (Col-0) ecotype was used in this study. Two Arabidopsis alkbh6 T-DNA insertion mutants (SALK_105865C and SALK_138864C) were obtained from the Arabidopsis Biological Resource Center (Columbus, OH, USA). The seeds were sterilized using $70 \%$ ethanol and $2 \% \mathrm{NaClO}$, and then washed with sterile water six times. The seeds were sown on half-strength Murashige and Skoog (MS) (Duchefa Biochemie, Haarlem, The Netherlands) medium containing $1 \%$ sucrose and were maintained at $4{ }^{\circ} \mathrm{C}$ for 3 days in darkness. The plants were grown in a growth room maintained at 23 $\pm 2{ }^{\circ} \mathrm{C}$ under long-day conditions ( $16 \mathrm{~h} \mathrm{light} / 8 \mathrm{~h}$ dark cycle).

\subsection{Germination and Seedling Growth Assays under Abiotic Stresses}

The wild-type and mutant seeds were harvested at the same time and were used for the analysis of germination and seedling growth, as described previously [63]. In short, to evaluate the effects of salt stress, drought stress, or ABA treatment on seed germination and seedling growth, the seeds were sown on solid MS medium supplemented with $100-250 \mathrm{mM} \mathrm{NaCl}, 200-400 \mathrm{mM}$ mannitol, or 1-4 $\mu \mathrm{M}$ ABA, respectively. For cold stress treatment, the MS plates containing the seeds were placed at $10^{\circ} \mathrm{C}$ under long-day conditions. For heat stress treatment, 3-day-old seedlings were treated at $37^{\circ} \mathrm{C}$ for $1 \mathrm{~h}$ and then subjected to heat stress at $45^{\circ} \mathrm{C}$ for $4 \mathrm{~h}$. Survival rate and fresh weight of the plants were measured seven days after heat treatment. Each seed was regarded as germinated when the radicle emerged from the seed coat. The fresh weight, root length, or survival rates of the seedlings were measured at different time points. To evaluate the effects of abiotic stress or ABA on root growth, the seeds were sown on the MS plates supplemented with $\mathrm{NaCl}$, mannitol, or $\mathrm{ABA}$, and the plates were placed in a vertical orientation. For drought stress treatment in soil, 6-day-old seedlings grown on MS medium were transferred to soil and were further grown for 14 days. Drought stress was applied by stopping watering for 13 days, and the recovery rate of each genotype was scored 3 days after re-watering. All experiments were repeated at least three times.

\subsection{Analysis of Subcellular Localization of the ALKBH6 Protein}

To generate the ALKBH6-green fluorescence protein (GFP) fusion construct, the cDNA encoding the full-length ALKBH6 was fused in front of the GFP gene using the BamHI/XbaI site in the CsV-GFP3-PA 
vector. The resulting plasmid was transformed into Agrobacterium tumefaciens GV3401, and the ALKBH6-GFP fusion protein was transiently expressed in tobacco leaves via Agrobacterium infiltration. The GFP signals emerging from the ALKBH6-GFP protein were observed using a confocal microscope (Carl Zeiss, Inc., Thornwood, NY, USA) with the excitation and emission wavelengths of 488 and 505-545 nm, respectively.

\subsection{RNA Extraction and Real-Time RT-PCR}

The plant samples collected at different time points were quickly frozen and ground to fine powder using a mortar and pestle in liquid nitrogen. Total RNA was extracted using the TRIzol reagent (GenAll ${ }^{\circledR}$ Hybrid-R ${ }^{\mathrm{TM}}$, Seoul, Korea), and the concentration of RNAs was qualified using a NanoDrop 2000 spectrophotometer (Thermo Scientific, Wilmington, DE, USA). To examine the level of gene expression, two hundred nanograms of total RNAs was used for RT-PCR and real-time qRT-PCR using a Rotor-Gene Q real-time thermal cycling system (Qiagen, Valencia, CA, USA) and QuantiTest SYBR Green RT-PCR kit (Qiagen) using the primers listed in Table S1. All experiments were repeated at least three times.

\subsection{Vector Construction and the Expression of Recombinant Protein in Escherichia coli}

To express the ALKBH6-His-taged fusion protein, the full-length cDNA encoding ALKBH6 was cloned into the pCold TF DNA vector (Takara, Shiga, Japan) using the BamHI/SalI sites. The resulting plasmid was transformed into the E. coli BL21 cell. After culturing the cells at $37^{\circ} \mathrm{C}$ until $\mathrm{OD}_{600}$ reached $0.4-0.8$, the cultures were quickly cooled to $15^{\circ} \mathrm{C}$ in ice water for $30 \mathrm{~min}$, after which the synthesis of the recombinant protein was induced by adding $0.1 \mathrm{mM} \mathrm{IPTG}$ at $15{ }^{\circ} \mathrm{C}$. The $E$. coli cells were collected, re-suspended in 1.0\% PBS, pH 7.4, and disintegrated by sonication. The ALKBH6-His-taged fusion protein was digested with the HRV 3 C protease (Takara), and the ALKBH6 protein was purified using a Ni-NTA His $\bullet$ Bind resin (Novagen, Temecula, CA, USA) using the elution buffer containing 250-500 mM imidazole. The total and purified proteins were analyzed via SDS-12\% PAGE.

\subsection{RNA-Protein Binding Assay}

RNA-protein binding assay was conducted as described previously [64]. In short, the $5^{\prime}$-fluoresceinlabeled RNA substrates with and without $\mathrm{m}^{6} \mathrm{~A}$ or $\mathrm{m}^{5} \mathrm{C}$ methylation were synthesized (BIONEER, Seoul, Korea). Approximately 3-7 $\mu \mathrm{M}$ of the purified recombinant protein was mixed with $5.0 \mathrm{pmol}$ of the synthetic RNA in a $20 \mu \mathrm{L}$ binding buffer $(10 \mathrm{mM}$ Tris- $\mathrm{HCl}, \mathrm{pH}$ 8.0, $150 \mathrm{mM} \mathrm{NaCl}, 1.0 \mathrm{mM}$ EDTA, and $10 \%$ glycerol) on ice for $30 \mathrm{~min}$. The RNA-protein mixture was loaded on a $6 \%$ polyacrylamide gel in $0.25 \times$ Tris/Borate/EDTA (TBE) at $4{ }^{\circ} \mathrm{C}$, and the binding products were detected using a FLA7000 image analyzer (GE Healthcare Life Sciences, Uppsala, Sweden).

\subsection{Measurement of the $m^{6} \mathrm{~A} / \mathrm{A}$ and $m^{5} \mathrm{C}$ levels}

Total RNA in seedlings was extracted using a Plant RNeasy extraction kit (Qiagen) following the manufacturer's instructions. The level of $\mathrm{m}^{6} \mathrm{~A}$ was determined using an EpiQuik $\mathrm{m}^{6} \mathrm{~A}$ RNA Methylation Quantification Kit (EPIGENTEK, Farmingdale, NY, USA), and the level of $\mathrm{m}^{5} \mathrm{C}$ was determined using a MethylFlash 5-mC RNA Methylation ELISA Easy Kit (EPIGENTEK) according to the manufacturer's instructions. In brief, 200 ng of RNA was bound to the assay wells containing an $\mathrm{m}^{6} \mathrm{~A}$ - or $\mathrm{m}^{5} \mathrm{C}$-specific antibody. The capture and detection antibody solutions were added, the signals for $\mathrm{m}^{6} \mathrm{~A}$ were quantified colorimetrically by reading the absorbance at $450 \mathrm{~nm}$, and the signals for $\mathrm{m}^{5} \mathrm{C}$ were quantified by measuring the fluorescence at the excitation and emission wavelengths of 530 and $590 \mathrm{~nm}$, respectively. The $\mathrm{m}^{6} \mathrm{~A}$ and $\mathrm{m}^{5} \mathrm{C}$ levels were calculated based on the constructed standard curves. 
Supplementary Materials: Supplementary materials can be found at http://www.mdpi.com/1422-0067/21/18/6707/ s1. Figure S1: Domain structures of the ALKB domain-containing proteins in Arabidopsis; Figure S2: The expression patterns of the stress-responsive marker genes in Arabidopsis; Figure S3: Confirmation of the T-DNA insertion alkbh6 mutants; Figure S4: Seed germination of the alkbh6 mutants under normal and abiotic stress conditions; Figure S5: Phenotypes of the alkbh6 mutants under normal growth conditions; Figure S6: Drought sensitivity of the alkbh6 mutants; Figure S7: Levels of m6A/A and m5C in the alkbh6 mutants; Figure S8: Purification of the recombinant ALKBH6 protein; Table S1: Gene-specific primer pairs used in this study.

Author Contributions: Conceptualization, H.K.; investigation, T.T.H. and L.N.T.N.; writing—original draft preparation, T.T.H.; writing-review and editing, H.K.; supervision, H.K.; funding acquisition, H.K. All authors have read and agreed to the published version of the manuscript.

Funding: This work was supported by a grant from the Next-Generation BioGreen21 Program (PJ01312201), Rural Development Administration, Republic of Korea.

Acknowledgments: We thank the Arabidopsis Biological Resource Center for providing the alkbh6-mutant seeds.

Conflicts of Interest: The authors declare no conflict of interest.

\section{Abbreviations}

ALKBH AlkB homolog

ABA Abscisic acid

GFP Green fluorescent protein

\section{References}

1. Saletore, Y.; Meyer, K.; Korlach, J.; Vilfan, I.D.; Jaffrey, S.; Mason, C.E. The birth of the epitranscriptome: Deciphering the function of RNA modification. Genome Biol. 2012, 13, 175. [CrossRef] [PubMed]

2. Meyer, K.D.; Jaffrey, S.R. The dynamic epitranscritome: N6-methyladenosine and gene expression control. Nat. Rev. Mol. Cell Biol. 2014, 15, 313-326. [CrossRef]

3. Cantara, W.A.; Crain, P.F.; Rozenski, J.; McCloskey, J.A.; Harris, K.A.; Zhang, X.; Vendeix, F.A.P.; Fabris, D.; Agris, P.F. The RNA modification database, RNAMDB: 2011 update. Nucleic Acids Res. 2011, 39, 195-201. [CrossRef] [PubMed]

4. Boccaletto, P.; Machicka, M.A.; Purta, E.; Piatkowski, P.; Baginski, B.; Wirecki, T.K.; de Crécy-Lagard, V.; Ross, R.; Limbach, P.A.; Kotter, A.; et al. MODOMICS: A database of RNA modification pathways. 2017 update. Nucleic Acids Res. 2018, 46, D303-D307. [CrossRef] [PubMed]

5. Sharma, S.; Lafontaine, D.L.J. 'View from a bridge': A new perspective on eukaryotic rRNA base modification. Trends Biochem. Sci. 2015, 40, 560-575. [CrossRef] [PubMed]

6. Chou, H.J.; Donnard, E.; Gustafsson, H.T.; Garber, M.; Rando, O.J. Transcriptome-wide analysis of roles for tRNA modifications in translational regulation. Mol. Cell 2017, 68, 978-992. [CrossRef]

7. Oerum, S.; Dégut, C.; Barraud, P.; Tisné, C. $\mathrm{m}^{1}$ A post-transcriptional modification in tRNAs. Biomolecules 2017, 7, 20. [CrossRef]

8. Helm, M. Post-transcriptional nucleotide modification and alternative folding of RNA. Nucleic Acids Res. 2006, 34, 721-733. [CrossRef]

9. Motorin, Y.; Helm, M. tRNA stabilization by modified nucleotides. Biochemistry 2010, 49, $4934-4944$. [CrossRef]

10. Baxter-Roshek, J.L.; Petrov, A.N.; Dinman, J.D. Optimization of ribosome structure and function by rRNA base modification. PLoS ONE 2007, 2, 174. [CrossRef]

11. Baudin-Baillieu, A.; Fabret, C.; Liang, X.; Piekna-Przybylska, D.; Fournier, M.J.; Rousset, J. Nucleotide modifications in three functionally important regions of the Saccharomyces cerevisiae ribosome affect translation accuracy. Nucleic Acids Res. 2009, 37, 7665-7677. [CrossRef] [PubMed]

12. Jackman, J.E.; Alfonzo, J.D. Transfer RNA modifications: Nature's combinatorial chemistry playground. Wiley Interdiscip. Rev. RNA 2013, 4, 35-48. [CrossRef] [PubMed]

13. Dominissini, D.; Nachtergaele, S.; Moshitch-Moshkovitz, S.; Peer, E.; Kol, N.; Ben-Haim, M.S.; Dai, Q.; Segni, A.D.; Salmon-Divon, M.; Clark, W.C.; et al. The dynamic N1-methyladenosine methylome in eukaryotic messenger RNA. Nature 2016, 530, 441-446. [CrossRef] [PubMed] 
14. Kawarada, L.; Suzuki, T.; Ohira, T.; Hirata, S.; Miyauchi, K.; Suzuki, T. ALKBH1 is an RNA dioxygenase responsible for cytoplasmic and mitochondrial tRNA modifications. Nucleic Acids Res. 2017, 45, 7401-7415. [CrossRef] [PubMed]

15. Lewis, C.J.; Pan, T.; Kalsotra, A. RNA modifications and structures cooperate to guide RNA-protein interactions. Nat. Rev. Mol. Cell Biol. 2017, 18, 202-210. [CrossRef] [PubMed]

16. Hu, J.Z.; Manduzio, S.; Kang, H.S. Epitranscriptomic RNA methylation in plant development and abiotic stress responses. Front. Plant Sci. 2019, 10, 500. [CrossRef] [PubMed]

17. Shen, L.; Liang, Z.; Wong, C.E.; Yu, H. Messenger RNA modifications in plants. Trends Plant Sci. 2019, 24, 328-341. [CrossRef]

18. Arribas-Hernández, L.; Brodersen, P. Occurrence and functions of $\mathrm{m}^{6} \mathrm{~A}$ and other covalent modifications in plant mRNA. Plant Physiol. 2020, 182, 79-96. [CrossRef]

19. Kim, J.; Shim, S.; Lee, H.; Seo, P.J. $\mathrm{m}^{6} \mathrm{~A}$ mRNA modification as a new layer of gene regulation in plants. J. Plant Biol. 2020, 63, 97-106. [CrossRef]

20. Bodi, Z.; Zhong, S.; Mehra, S.; Song, J.; Graham, N.; Li, H.; May, S.; Fray, R.G. Adenosine methylation in Arabidopsis mRNA is associated with the $3^{\prime}$ end and reduced levels cause developmental defects. Front. Plant Sci. 2012, 3, 48. [CrossRef]

21. Shen, L.; Liang, Z.; Gu, X.; Chen, Y.; Teo, Z.W.N.; Hou, X.; Cai, W.M.; Dedon, P.C.; Liu, L.; Yu, H. $\mathrm{N}^{6}$-methyladenosine RNA modification regulates shoot stem cell fate in Arabidopsis. Dev. Cell 2016, 38, 186-200. [CrossRef] [PubMed]

22. Růžička, K.; Zhang, M.; Campilho, A.; Bodi, Z.; Kashif, M.; Saleh, M.; Eeckhout, D.; El-Showk, S.; Li, H.; Zhong, S.; et al. Identification of factors required for $\mathrm{m}^{6} \mathrm{~A}$ mRNA methylation in Arabidopsis reveals a role for the conserved E3 ubiquitin ligase HAKAI. New Phytol. 2017, 215, 157-172. [CrossRef]

23. Arribas-Hernández, L.; Bressendorff, S.; Hansen, M.H.; Poulsen, C.; Erdmann, S.; Brodersen, P. An m ${ }^{6}$ A-YTH module controls developmental timing and morphogenesis in Arabidopsis. Plant Cell 2018, 30, 952-967. [CrossRef] [PubMed]

24. Scutenaire, J.; Deragon, J.M.; Jean, V.; Benhamed, M.; Raynaud, C.; Favory, J.J.; Merret, R.; Bousquet-Antonelli, C. The YTH domain protein ECT2 is an $\mathrm{m}^{6} \mathrm{~A}$ reader required for normal trichome branching in Arabidopsis. Plant Cell 2018, 30, 986-1005. [CrossRef] [PubMed]

25. Wei, L.-H.; Song, P.; Wang, Y.; Lu, Z.; Tang, Q.; Yu, Q.; Xiao, Y.; Zhang, X.; Duan, H.-C.; Jia, G. The $\mathrm{m}^{6} \mathrm{~A}$ reader ECT2 controls trichome morphology by affecting mRNA stability in Arabidopsis. Plant Cell 2018, 30, 968-985. [CrossRef]

26. Fedeles, B.I.; Singh, V.; Delaney, J.C.; Li, D.; Esigmann, J.M. The AlkB family of Fe(II)/ $\alpha$-ketoglutarate-dependent dioxygenases: Repairing nucleic acid alkylation damage and beyond. J. Biol. Chem. 2015, 290, 20734-20742. [CrossRef]

27. Alemu, E.A.; He, C.; Klungland, A. ALKBHs-facilitated RNA modifications and de-modifications. DNA Rep. 2016, 44, 87-91. [CrossRef]

28. Kurowski, M.A.; Bhagwat, A.S.; Papaj, G.; Bujnicki, J.M. Phylogenomic identification of five new human homologs of the DNA repair enzyme AlkB. BMC Genom. 2003, 4, 1-6. [CrossRef]

29. Gerken, T.; Girard, C.A.; Tung, Y.C.; Webby, C.J.; Saudek, V.; Hewitson, K.S.; Yeo, G.S.H.; McDonough, M.A.; Cunliffe, S.; McNeill, L.A.; et al. The obesity-associated FTO gene encodes a 2-oxoglutarate-dependent nucleic acid demethylase. Science 2007, 318, 1469-1472. [CrossRef]

30. Mielecki, D.; Zugaj, D.L.; Muszewska, A.; Piwowarski, J.; Chojnacka, A.; Mielecki, M.; Nieminuszczy, J.; Grynberg, M.; Grzesiuk, E. Novel AlkB dioxygenases- alternative models for in silico and in vivo studies. PLOS ONE 2012, 7, e30588. [CrossRef]

31. Ougland, R.; Rognes, T.; Klungland, A.; Larsen1, E. Non-homologous functions of the AlkB homologs. Mol. Cell Biol. 2015, 7, 494-504. [CrossRef] [PubMed]

32. Marcinkowski, M.; Pilžys, T.; Garbicz, D.; Steciuk, J.; Zugaj, D.; Mielecki, D.; Sarnowski, T.Z.; Grzesiuk, E. Human and Arabidopsis alpha-ketoglutarate-dependent dioxygenase homolog proteins-New players in important regulatory processes. IUBMB Life 2020, 72, 1126-1144. [CrossRef] [PubMed]

33. Jia, G.; Fu, Y.; Zhao, X.; Dai, Q.; Zheng, G.; Yang, Y.; Yi, C.; Lindahl, T.; Pan, T.; Yang, Y.-G.; et al. N6-methyladenosine in nuclear RNA is a major substrate of the obesity-associated FTO. Nat. Chem. Biol. 2011, 7, 885-887. [CrossRef] [PubMed] 
34. Zheng, G.; Dahl, J.A.; Niu, Y.; Fedorcsak, P.; Huang, C.M.; Li, C. ALKBH5 is a mammalian RNA demethylase that impacts RNA metabolism and mouse fertility. Mol. Cell 2013, 49, 18-29. [CrossRef]

35. Duan, H.-C.; Wei, L.-H.; Zhang, C.; Wang, Y.; Chen, L.; Lu, Z.; Chen, P.R.; He, C.; Jia, G. ALKBH10B is an RNA N ${ }^{6}$-methyladenosine demethylase affecting Arabidopsis floral transition. Plant Cell 2017, 29, 2995-3011. [CrossRef]

36. Martínez-Pérez, M.; Aparicio, F.; López-Gresa, M.P.; Bellés, J.M.; Sánchez-Navarro, J.A.; Pallás, V. Arabidopsis $\mathrm{m}^{6} \mathrm{~A}$ demethylase activity modulates viral infection of a plant virus and the $\mathrm{m}^{6} \mathrm{~A}$ abundance in its genomic RNAs. Proc. Natl. Acad. Sci. USA 2017, 114, 10755-10760. [CrossRef]

37. Zhou, L.; Tian, S.; Qin, G. RNA methylomes reveal the $\mathrm{m}^{6} \mathrm{~A}$-mediated regulation of DNA demethylase gene SIDML2 in tomato fruit ripening. Genome Biol. 2019, 20, 156. [CrossRef]

38. Ma, S.; Gong, Q.; Bohnert, H.J. Dissecting salt stress pathways. J. Exp. Bot. 2006, 57, 1097-1107. [CrossRef]

39. Merret, R.; Nagarajan, V.K.; Carpentier, M.-C.; Park, S.; Favory, J.-J.; Descombin, J.; Picart, C.; Charng, Y.-Y.; Green, P.J.; Deragon, J.-M.; et al. Heat-induced ribosome pausing triggers mRNA co-translational decay in Arabidopsis thaliana. Nucleic Acids Res. 2015, 43, 4121-4132. [CrossRef]

40. Luo, G.-Z.; MacQueen, A.; Zheng, G.; Duan, H.; Dore, L.C.; Lu, Z.; Liu, J.; Chen, K.; Jia, G.; Bergelson, J.; et al. Unique features of the $\mathrm{m}^{6} \mathrm{~A}$ methylome in Arabidopsis thaliana. Nat. Commun. 2014, 5, 5630. [CrossRef]

41. Pendleton, K.E.; Chen, B.; Liu, K.; Hunter, O.V.; Xie, Y.; Tu, B.P.; Conrad, N.K. The U6 snRNA m ${ }^{6}$ A methyltransferase METTL16 regulates SAM synthetase intron retention. Cell 2017, 169, 824-835. [CrossRef] [PubMed]

42. Cui, X.; Liang, Z.; Shen, L.; Zhang, Q.; Bao, S.; Geng, Y.; Zhang, B.; Leo, V.; Vardy, L.A.; Lu, T.; et al. 5-methylcytosine RNA methylation in Arabidopsis thaliana. Mol. Plant 2017, 10, 1387-1399. [CrossRef] [PubMed]

43. Hampton, C.R.; Bowen, H.C.; Broadley, M.R.; Hammond, J.P.; Mead, A.; Payne, K.A.; Pritchard, J.; White, P.J. Cesium toxicity in Arabidopsis. Plant Physiol. 2004, 136, 3824-3837. [CrossRef] [PubMed]

44. Tang, Y.; Gao, C.-C.; Gao, Y.; Yang, Y.; Shi, B.; Yu, J.-L.; Lyu, C.; Sun, B.-F.; Wang, H.-L.; Xu, Y.; et al. OsNSUN2-mediated 5-methylcytosine mRNA modification enhances rice adaptation to high temperature. Dev. Cell 2020, 53, 1-15. [CrossRef]

45. Anderson, S.J.; Kramer, M.C.; Gosai, S.J.; Yu, X.; Vandivier, L.E.; Nelson, A.D.; Anderson, Z.D.; Beilstein, M.A.; Fray, R.G.; Lyons, E.; et al. $\mathrm{N}^{6}$-methyladenosine inhibits local ribonucleolytic cleavage to stabilize mRNAs in Arabidopsis. Cell Rep. 2018, 25, 1146-1157. [CrossRef]

46. Finkelstein, R.R. Abscisic acid synthesis and response. Arab. Book 2013, 11, e0166. [CrossRef]

47. Giraudat, J.; Hauge, B.M.; Valon, C.; Smalle, J.; Parcy, F.; Goodman, H.M. Isolation of the Arabidopsis ABI3 gene by positional cloning. Plant Cell 1992, 4, 1251-1261.

48. Finkelstein, R.R.; Wang, M.L.; Lynch, T.J.; Rao, S.; Goodman, H.M. The Arabidopsis abscisic acid response locus ABI4 encodes an APETALA 2 domain protein. Plant Cell 1998, 10, 1043-1054. [CrossRef]

49. Finkelstein, R.R.; Lynch, T.J. The Arabidopsis abscisic acid response locus ABI5 encodes a basic leucin zipper transcription factor. Plant Cell 2000, 12, 599-609. [CrossRef]

50. Cutler, S.R.; Rodriguez, P.L.; Finkelstein, R.R.; Abrams, S.R. Abscisic acid: Emergence of a core signaling network. Annu. Rev. Plant Biol. 2010, 61, 651-679. [CrossRef]

51. Reeves, W.M.; Lynch, T.J.; Mobin, R.; Finkelstein, R.R. Direct targets of the transcription factors ABA-insensitive (ABI4 and ABI5) reveal synergistic action by ABI4 and several bZIP ABA response factors. Plant Mol. Biol. 2011, 75, 347-363. [CrossRef] [PubMed]

52. Feng, C.Z.; Chen, Y.; Wang, C.; Kong, Y.H.; Wu, W.H.; Chen, Y.F. Arabidopsis RAV1 transcription factor, phosphorylated by SnRK2 kinases, regulates the expression of $A B I 3, A B I 4$, and $A B I 5$ during seed germination and early seedling development. Plant J. 2014, 80, 654-668. [CrossRef] [PubMed]

53. Wang, X.; Lu, Z.; Gomez, A.; Hon, G.C.; Yue, Y.; Han, D.; Fu, Y.; Parisien, M.; Dai, Q.; Jia, G.F.; et al. $\mathrm{N}^{6}$-methyladenosine-dependent regulation of messenger RNA stability. Nature 2014, 505, 117-120. [CrossRef]

54. Du, H.; Zhao, Y.; He, J.; Zhang, Y.; Xi, H.; Liu, M.; Ma, J.B.; Wu, L. YTHDF2 destabilizes m ${ }^{6}$ A-containing RNA through direct recruitment of the CCR4-NOT deadenylase complex. Nat. Commun. 2016, 7, 12626. [CrossRef] [PubMed]

55. Huang, H.; Weng, H.; Sun, W.; Qin, X.; Shi, H.; Wu, H.; Zhao, B.S.; Mesquita, A.; Liu, C.; Yuan, C.L.; et al. Recognition of RNA N ${ }^{6}$-methyladenosine by IGF2BP proteins enhances mRNA stability and translation. Nat. Cell Biol. 2018, 20, 285-295. [CrossRef] 
56. Clark, W.C.; Evans, M.E.; Dominissini, D.; Zheng, G.; Pan, T. tRNA base methylation identification and quantification via high-throughput sequencing. RNA 2016, 22, 1-14. [CrossRef]

57. Sergiev, P.V.; AAleksashin, N.A.; Chugunova, A.A.; Polikanov, Y.S.; Dontsova, O.A. Structural and evolutionary insights into ribosomal RNA methylation. Nat. Chem. Biol. 2018, 14, 226-235. [CrossRef]

58. Wen, J.; Lv, R.; Ma, H.; Shen, H.; He, C.; Wang, J.; Jian, F.; Liu, H.; Yang, P.; Tan, L.; et al. Zc3h13 regulates nuclear RNA m ${ }^{6}$ A methylation and mouse embryonic stem cell self-renewal. Mol. Cell 2018, 69, 1028-1038. [CrossRef]

59. Zhang, F.; Zhang, Y.-C.; Liao, J.-Y.; Yu, Y.; Zhou, Y.-F.; Feng, Y.-Z.; Yang, Y.-W.; Lei, M.-Q.; Bai, M.; Wu, H.; et al. The subunit of RNA N6-methyladenosine methyltransferase OsFIP regulates early degeneration of microspores in rice. PLoS Genet. 2019, 15, e1008120. [CrossRef]

60. Aoyama, T.; Yamashita, S.; Tomita, K. Mechanistic insights into $\mathrm{m}^{6} \mathrm{~A}$ modifications of U6 snRNA by human METTL16. Nucleic Acids Res. 2020, 48, 5157-5168. [CrossRef]

61. Tsujikawa, K.; Koike, K.; Kitae, K.; Shinkawa, A.; Arima, H.; Suzuki, T.; Tsuchiya, M.; Makino, Y.; Furukawa, T.; Konishi, N.; et al. Expression and sub-cellular localization of human ABH family molecules. J. Cell. Mol. Med. 2007, 11, 1105-1116. [CrossRef] [PubMed]

62. Sedgwick, B.; Bates, P.A.; Paik, J.; Jacobs, S.C.; Lindahl, T. Repair of alkylated DNA: Recent advances. DNA Repair (Amst.) 2007, 6, 429-442. [CrossRef] [PubMed]

63. Dinh, S.N.; Park, S.J.; Han, J.H.; Kang, H. A chloroplast-targeted S1 RNA-binding domain protein plays a role in Arabidopsis response to diverse abiotic stresses. J. Plant Biol. 2019, 62, 74-81. [CrossRef]

64. Lee, K.; Park, S.J.; Colas des Francs-Small, C.; Whitby, M.; Small, I.; Kang, H. The coordinated action of PPR4 and EMB2654 on each intron half mediates trans-splicing of rps12 transcripts in plant chloroplasts. Plant J. 2019, 100, 1193-1207. [CrossRef] [PubMed]

(C) 2020 by the authors. Licensee MDPI, Basel, Switzerland. This article is an open access article distributed under the terms and conditions of the Creative Commons Attribution (CC BY) license (http://creativecommons.org/licenses/by/4.0/). 